\title{
Isolation, identification and characterization of Cytospora chrysosperma associated with canker disease of Salix alba $\mathrm{L}$.
}

\author{
Sabina Rana ${ }^{\star}$, Sunita Chandel** and Sanjeev Thakur*** \\ Department of Biotechnology, College of Horticulture, Dr. Y. S. Parmar University of Horticulture and Forestry, Nauni, Solan-173230, Himachal \\ Pradesh, India \\ *Department of Plant Pathology, College of Horticulture, Dr. Y. S. Parmar University of Horticulture and Forestry, Nauni, Solan-173230, \\ Himachal Pradesh, India \\ **Department of Tree Improvement and Genetic Resources, College of Forestry, Dr. Y. S. Parmar University of Horticulture and Forestry, Nauni, \\ Solan-173230, Himachal Pradesh, India
}

\section{Article Info}

Article history

Received 1 November 2021

Revised 17 December 2021

Accepted 19 December 2021

Published Online 30 December 2021

\section{Keywords}

Cytospora chrysosperma

Salix alba $\mathrm{L}$.

Pathogenicity

Canker

Tree

\begin{abstract}
A serious canker disease associated with Salix alba L. tree in the cold desert of Kinnaur district of Himachal Pradesh, India was thoroughly explored for molecular and morphological identification and characterization. The samples were collected from canker infected trees of $S$. alba, which showed typical symptoms of the disease on the branches and twigs. Isolation of the pathogen was done on potato dextrose agar (PDA) medium as per the standard isolation technique and designated initially on the basis of morphology and cultural characteristics. Further, the sequence data obtained from the amplified ITSrDNA region and its retrieval and comparison with the data available in GenBank confirmed initially the strain as Cytospora chrysosperma. In vivo and in vitro pathogenicity test of isolate (C. chrysosperma) on shoots of S.alba induced the symptoms of canker disease. These preliminary studies have provided ITS sequence data for the pathogen which has been deposited in GenBank as Valsa sordida isolate SR91 to further improve the understanding of the C. chrysosperma on the other woody host.
\end{abstract}

\section{Introduction}

Salix also known as Willow is a fast growing and short-rotation species, of Salicaceae. It is mainly grow through the vegetative propagation, and is cross compatible, having nineteen basic chromosome number (Mabberley, 1997). In India, approximately 33 species of Salix have been reported in the temperate regions covering 137,300 ha of land (Country Report on Poplars and Willows 2012-2015, National Poplar Commission of India). Salix is a biomass producing plant having wide adaptability. Bioactive compound, salicylic acid present in the young twigs and bark of the plant have been utilized to cure headaches. It is also a source of biofuel and bioenergy production. Moreover, the Willow trees have practical application in restoring damaged ecosystems, controlling soil erosion, nutrient recycling and phytoremediation (Granel et $a l ., 2002)$. Being a perennial tree, Willow has many potential biotic constrains during its life span but fungal infestation is one of the most prevalent and damaging diseases.

In general, Cytospora species cause most serious epidemic disease, canker usually observe on Salix, aspen and other woody plant species throughout the world and affecting a number of other

Corresponding author: Dr. Sabina Rana

Department of Biotechnology, College of Horticulture, Dr. Y.S. Parmar University of Horticulture and Forestry, Nauni, Solan-173230, Himachal Pradesh, India

E-mail: sabinarana.90@gmail.com

Tel.: +91-8894689779

Copyright $\odot 2021$ Ukaaz Publications. All rights reserved.

Email: ukaaz@yahoo.com; Website: www.ukaazpublications.com horticultural and commercially important trees, viz., apples, plums and birches (Limb et al., 2003; Marshall et al., 2013). Some of these fungal species are host-specific while other can infect several different trees resulting in mortality of the host plant due to the attack of asexual and sexual spores on freshly wounded tissues causing death of planted trees (Tisserat, 2004). Unfortunately, understanding and distribution of Cytospora species is lacking in Himachal Pradesh and in other parts of India. Cytospora refers to the Latin name of asexual stages of these fungi (Sinclair et al., 1987) which has been used over others, viz., Leucocytospora, Valsa and valsella, etc. (Rossman et al., 2015). Donk (1964) clarified that the type species of Cytospora, C. chrysosperma is the asexual morph of Valsa sordida and is responsible for causing cankers on the members of Salicaceae (Callan, 1998). It is also a limiting factor in the establishment and growth of the Willows. A survey conducted in the year 2007 to predict the distribution and status of Willows in Lahaul and Spiti district of cold desert regions of Himalayas revealed high Willow mortality (approximately 2 to $93.8 \%$ ) due to canker caused by C. chrysosperma (Sharma et al., 2011).

Therefore, in the current study, the impact of C. chrysosperma on plantation of Willow in Kinnaur district of Himachal Pradesh for continuous three years (2016-18) was deciphered. The primary objective was to isolate, identify and then to characterize $C$. chrysosperma causing a canker disease of Salix in North India for the first time. Morphological and molecular data along with assessment of the pathogenicity of isolated culture in in vivo and in vitro conditions was done to develop some effective controls for 
Cytospora canker by using various crop improvement techniques in future because other methods of cultivation and use of chemicals to manage this disease on planted trees are laborious, time consuming and expensive.

\section{Materials and Methods}

2.1 Sampling; isolation; identification of pathogen and maintenance of culture

Salix trees showing symptoms of canker on twigs, shoots and stem were targeted for sample collection (Figures 1a and b). Pathogen responsible for canker infection was isolated (Figures 1c and d) from these samples.

Severely canker infected branches and twigs of $S$. alba were identified and collected from diverse regions of Kinnaur district. Isolation of $C$. chrysosperma from diseased tissue was performed using standard protocol: (i) Seven diseased samples (P1 to P7) were collected from seven different plants and were washed under running tap water, followed by cutting into small bits $(0.5-1.0 \mathrm{~cm})$ using sterilized blade. (ii) Further, bits were sterilized via dipping for $1 \mathrm{~min}$ in Bavistin $(0.2 \% \mathrm{w} / \mathrm{v})$ followed by $5 \mathrm{~min}$ in $0.5 \%$ sodium hypochlorite $(\mathrm{NaOCl})$ and finally washed thrice with distilled water (iii) Bits were dried on filter paper (sterilized) to avoid excess moisture and were inoculated on potato dextrose agar (PDA, Difco Laboratory, Detroit, MI, USA), plates (three Petri plates/samples) and incubated at $25 \pm 2{ }^{\circ} \mathrm{C}$ which were frequently visualized for mycelia growth. (iv) These were identified on morphological and cultural basis (Long et al.,1918; Arzanlou et al., 2012) like growth, type, color of mycelia and development of conidia and pycnidia.

From isolated and tentatively identified three cultures of $C$. chrysosperma, single conidia/pycnidia was picked from PDA plates and cultured on PDA slants (S1, S3 and S7) at pH 5.6 and incubated at $25 \pm 2{ }^{\circ} \mathrm{C}$ for a week until uniform fluffy white colored mycelia growth was observed.

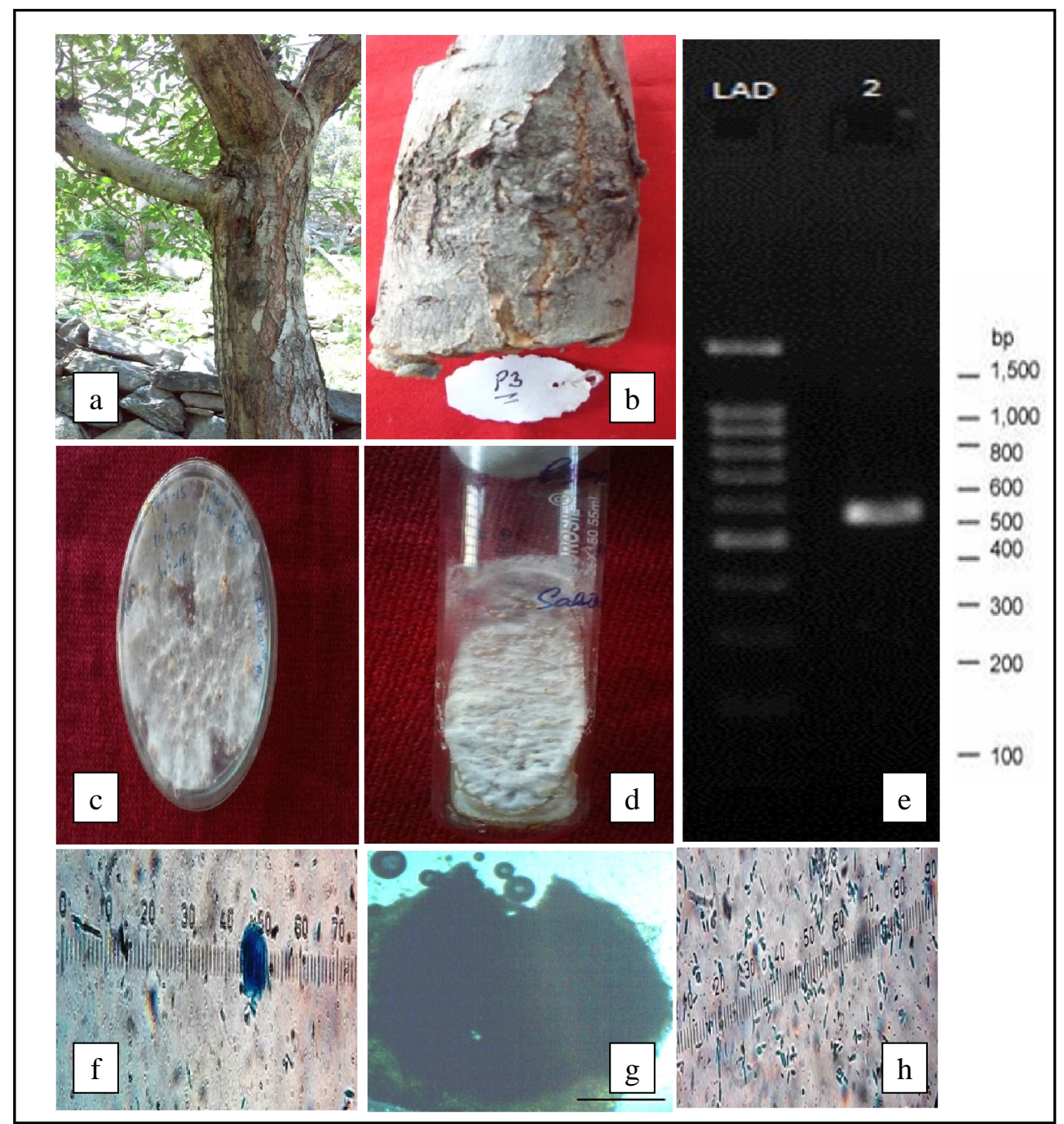

Figure 1: Isolation and identification of the fungus: (a) Diseased plant, (b) Diseased sample, (c) Putative culture of Cytospora chrysosperma isolated from diseased sample, (d) Pure culture of Cytospora chrysosperma isolated from diseased sample, (e) Amplified ITS region of the fungus, (f-h) Light microscopic view of of Cytospora chrysosperma (occular microscopyf. Pycnidiag. Pycnidia (close view) h. Conidia) Bar: $d=20 \mu \mathrm{m}$ 


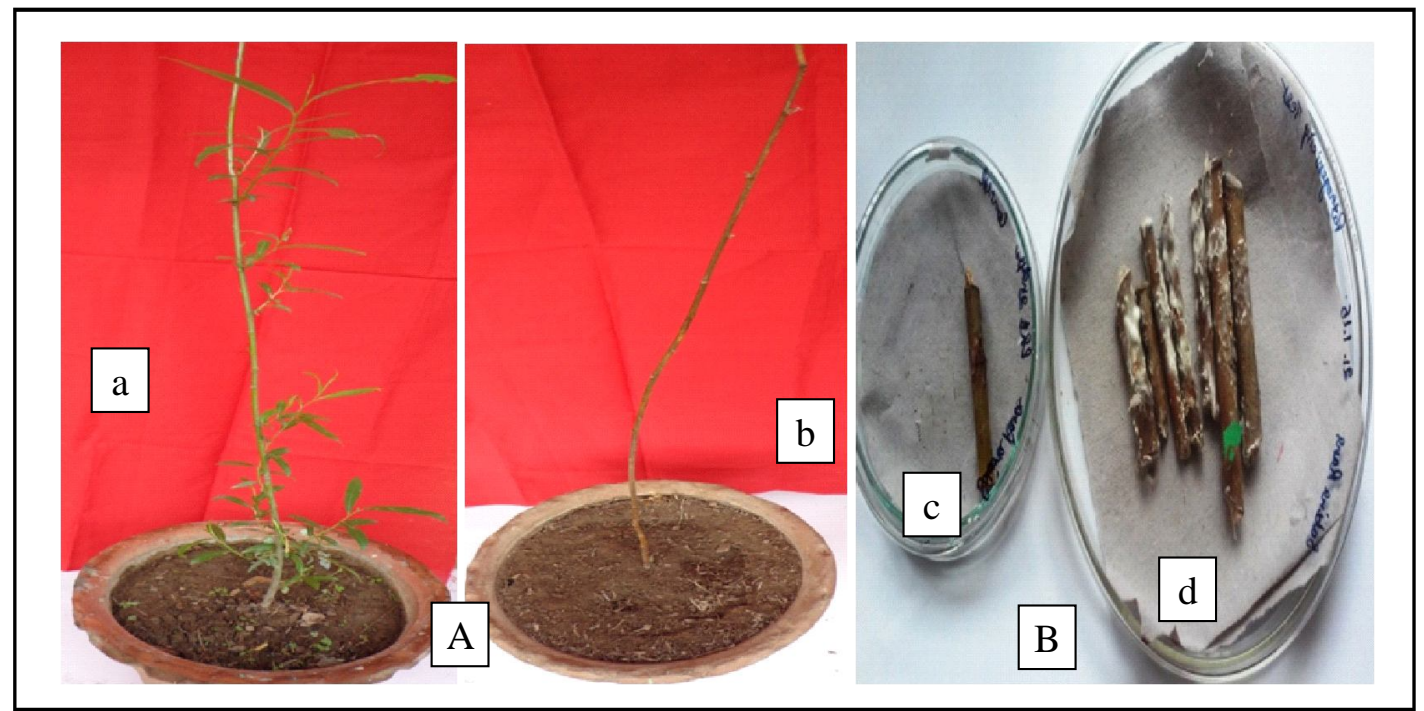

Figure 2: Testing the pathogenicity of fungus Cytospora chrysosperma (A) In vivo testing: (a) Control plant, (b) Plant after 15 days of inoculation with S3 suspension, (B) In vitro testing: (c) Control shoots, (d) Shoots after 15 days of inoculations with S3 suspension.

Slants containing purified culture (S3) were maintained, covered properly and stored at $5^{\circ} \mathrm{C}$ for further study. Ocular micrometer was used for scaling of pycnidia and conidia that were visualized under the high power (400X) microscope. These tentatively identified cultures were sent to National Center of Fungal Taxonomy, New Delhi (NCFT) for confirmation down to species level.

\subsection{Confirmation of pathogenicity}

The mycelial mat from slants of three isolated and partially identified cultures were homogenized in distilled water and obtained mixture was passed through the muslin cloth for the testing of pathogenicity.

Six plants of $S$. alba were raised in pots and three shoots (one year old) along with stem were pin pricked to make wounds. Freshly prepared 15 days old $10 \mathrm{ml}$ of mycelia suspension from three isolates (S1, S3 and S7) containing approx. $12 \times 10^{-4}$ conidial spores were sprayed on two plants per isolate at wounded areas of shoots and were covered with moist cotton plug and parafilm. Autoclaved distilled water was taken as control. The plants were observed for canker disease appearance and kept for observation under polyhouse conditions.

Evaluation of pathogenicity was also performed under laboratory conditions (Arzanlou et al., 2012) on excised shoots (1-year old shoots; $10-15 \mathrm{~mm}$ diameter; $8-10 \mathrm{~cm}$ in length) from healthy trees. For inoculation, shoots were first sterilized with $70 \%$ ethanol and then wounded randomly at 4-5 places utilizing sterile metal cork borer. Mycelia obtained from seven-day old fungal colony of three isolates (which were also used in field condition S1, S3 and S7) were placed on to the wounds of shoots using moist cotton plug. It was then covered with parafilm. Control samples were maintained with distilled water on wound. Shoots inoculated with three isolates were placed on three different Petri Plates, respectively with moist filter paper to maintain relative high humidity and were kept under $25^{\circ} \mathrm{C}$ with natural daylight. To check the disease progression, shoots were analyzed after 28 days and length of necrosis, discoloration and pycnidia on inoculated shoot were used as an indicator of pathogenicity. An experiment was conducted to fulfill the Koch's postulates and attempt was made to isolate the same pathogen from inoculated shoots used in in vitro testing. Healthy samples were taken as control.

\section{Fungal isolates for molecular characterization using ITS marker}

3.1 Genomic DNA extraction and characterization of isolate using ITS primers

Total genomic DNA were isolated from fungal isolate S3, using modified CTAB method (Doyle and Doyle, 1990). Quantity and quality of DNA was determined using Nano Drop $2000 \mathrm{OD}_{260}$ l $\mathrm{OD}_{280}$ and integrity using $0.8 \%$ agarose gel. Genomic DNA of fungal isolate was amplified using universal primers from ITS region of fungus. PCR amplification was performed using $40 \mathrm{ng}$ of genomic DNA, $0.5 \mu 1$ of each ITS-1 (5'TCCGTAGGTGAACCTGCGG3') and ITS-4 (5'TCCTCCGCTTATTGATATGC3') primers (10 nmol), 0.1 $\mu 1$ of dNTPs $(500 \mu \mathrm{M}), 1 \mu 1$ of $\mathrm{MgCl}_{2}(1.5 \mathrm{mM}), 1.5 \mu 1$ of $10 \mathrm{X}$ buffer, $1 \mathrm{U}$ Taq DNA polymerase to make final reaction volume 10 $\mu 1$. PCR cycles were kept for pre-denaturation at $94^{\circ} \mathrm{C}$ for $3 \mathrm{~min}, 35$ cycles of denaturation at $94^{\circ} \mathrm{C}$ for $30 \mathrm{sec}$, annealing at $50^{\circ} \mathrm{C}$ for 30 sec followed by extension step of PCR at $72^{\circ} \mathrm{C}$ for a min and final extension for $7 \mathrm{~min}$ at $72^{\circ} \mathrm{C}$. Amplified PCR products were separated on $2 \%$ agarose gel and size was determined against 1500 bp ladder and visualized under UV trans-illuminator (BioRad).

\subsection{Sequencing of ITS region and BLASTn analysis}

Amplified PCR product with ITS primers was sent for sequencing to Eurofins Genomics India Pvt. Ltd., Bengaluru, India. Sequence information retrieved after sequencing from both directions was assessed for homology. The complete sequence was BLASTn searched for sequence homology identification within genera by limiting the search to organisms of Cytospora chrysosperma and Valsa sordida. 


\section{Results}

4.1 Pathogen isolation, multiplication and maintenance of pure culture

\subsubsection{Morphological characters}

It is evident from the cultures that the fungus grown well on all PDA Figures (Figure $1 \mathrm{c}$ ) at $25^{\circ} \mathrm{C}$ and those three colonies from samples $\mathrm{P} 1, \mathrm{P} 3$ and $\mathrm{P} 7$ which attained a diameter of $40 \mathrm{~mm}$ producing whitish mycelia were subcultured on PDA slants (S1, S3 and S7, respectively) (Figure $1 \mathrm{~d}$ ) that changed to brown colour in 15 days. Conidia from all three isolates were visualized under microscope and pycnidia from S3 with both microscope and naked eye. Mycelia grown like white cotton and spreads rapidly along the sides of tube. In seven to ten days, at room temperature, mycelia colour changed from yellow beige to brown to black. After twenty days, small pycnidia of $\sim 0.4$ to $1 \mathrm{~mm}$ were developed in test tubes of isolate $\mathrm{S} 3$ at the edge and centre. Further, ocular microscopic results revealed black pycnidia with globose base and small, hyaline pycnidiospores discharged from the top of pycnidium. Conidio phores were hyaline to dark greenish brown andhyaline conidia were produced in chains (Figures $1 \mathrm{f}, \mathrm{g}, \mathrm{h}$ ). The size of conidia was ranged from $2.5-4.5 \times 0.3-1.0 \mu \mathrm{m}(\mathrm{n}=10)$.

\subsubsection{Species Identification}

Only isolate S3 from plant P3 (Figure $1 \mathrm{~d}$ ) showed the characteristics of the canker causing fungus as identified morphologically and by sending the cultures to NCFT, New Delhi for identification upto the species level. The identity of the pathogen was confirmed by NCFT as $C$. chrysosperma on the basis of morphological and cultural characters as mentioned above (for isolate S3) vide identification no.7837.16, dated 03/05/2016.

\subsection{Pathogenicity of fungus}

Before using the fungal strains for further study, pathogenicity tests were performed.

\subsubsection{In vivo testing}

In order to obtain the results of the pathogenicity test of fungus in vivo, plants of Salix were taken and sprayed with fungal suspension and control plants with distilled water. The perusal of the findings indicates that after 15 days, typical symptoms of canker started appearing on both plants sprayed with fungal suspension S3, viz., development of pycnidia, discoloration, stunted growth, necrosis and dieback. Other isolates (S1 and S7) did not show such symptoms. However, no symptoms were observed in control samples (Figure 2A).

\subsubsection{In vitro testing}

Pathogenicity assay performed on shoots of Salix revealed similar symptoms as observed in field testing. Only inoculated shoots with isolate $\mathrm{S} 3$ showed canker disease progression and pycnidia in 28 days. No symptoms were there in control shoots (Figure 2B). Koch's postulates were fulfilled as the same pathogen was reisolated from inoculated shoots used in in vitro testing and not from healthy samples. It was observed that its morphological and cultural parameters were similar to the mother inoculant.

\subsection{Amplification of isolated fungus using ITS marker}

Amplification of isolated fungal DNA (from isolate S3) with ITS1 and ITS4 primers carried out successful amplification of entire ITS region along with $5.8 \mathrm{~S}$ gene with an amplicon size of approximately 500 bp (Figure 1 e).

\subsubsection{Sequencing}

After sequencing of ITS region, the size obtained was $531 \mathrm{bp}$. The sequence was submitted in NCBI as Valsa sordida isolate SR91 (GenBank accession no. MK288138).

\subsubsection{In silico analysis of the sequences}

BLASTn analysis of ITS sequence with GenBank database of (http:/ /www.ncbi.nlm.nih.gov/blast) Cytospora chrysosperma and Valsa sordida revealed its homology with various other closest gene sequences of this genus. The sequence revealed maximum similarity of $93 \%$ with C. chrysosperma (Sequence Id: KP114135.1).

Interestingly, both morphological and molecular characterization (BLASTn analysis) of Cytospora isolate S3 concluded that the isolated fungus identified in current study is C. chrysosperma, which was further supported by NCFT results.

\section{Discussion}

Cytospora canker is devastating for forest as well as urban trees causing mortality and dieback of these woody hosts. A number of studies have been carried out for isolation and characterization of this fungus from various plants for understanding of its host range, geographical relationships (Kepley, 2000; Adams et al., 2006), genetic diversity (Abbasi et al., 2011), physiology to reduce the damage (Mehrabi et al., 2011), morphological and phylogenetic studies (Fan et al., 2014), etc.

In the present study, some fungal isolates were isolated from canker infected twigs, branches as well as stems of diseased Salix trees, particularly isolating a canker causing fungus $C$. chrysosperma that appears to be an important pathogen on Salix in cold desert area of North India as well as other parts of the world. In an investigation done by Fan et al. (2019), it was found that the favorable conditions for occurrence of Cytospora spp. are dry and cold environment. In this study, isolated fungus is described by three parameters: (i) morphological and cultural, (ii) pathogenicity, (iii) molecular approach based on DNA sequencing for depicting the relationship of the identified fungus and its relatives using BLAST.

Colonies grewn well on PDA medium which is a general-purpose medium for molds and yeasts. Phenotypic and cultural characteristics of the isolated pathogen of the present study are in agreement with the previous reports of isolation of C. chrysosperma (Long et al.,1918; Adams et al., 2006; Goltapeh et al., 2011; Arzanlou et al.2012). Currently, a morphological approach for identification of any species is considered as some what unreliable as these characters can differ among various species due to attributes of host bark and cambium (Wang et al., 2016), although traditionally structures produced by a sexual and sexual reproduction were described exclusively for fungal species identification, i.e., characters based on morphology of perithecia or pycnidia including locule and spore's shape and dimensions, respectively (Grove, 1923; Spielman, 1985). In species under Cytospora genera, previous studies have concluded it as species complex due to shared morphological 
characteristics but also recommending DNA sequencing as a tool for resolving its identification (Adams et al., 2004).

Pathogenicity is the ability of a pathogen to infect. For inoculation of canker causing fungi, pathogen penetration ability in the host is intensified by wounding of the young tree. Thus, for this study, before proceeding to the molecular identification, pathogenicity tests were carried out in lab and field. The putative pathogen was inoculated on the host surface artificially, by imposing wounds and then keeping the respective area in moist condition. Pathogenicity evaluations are necessary to observe the relation between the species and symptoms however, in case of Cytospora spp., their outcomes are variable. Lawrence et al. (2017) examined Cytospora isolates from dieback and wood cankers of grapevine in U.S. and Canadian provinces for understanding the trunk disease complex. They perform the pathogenicity test for two novel species: C.vinacea and $C$. viticola on potted plants of Vitis vinifera, which were grown under green house. The lesion length was observed after twelve months showing pathogenic nature of both the species indicating Cytospora viticola more virulent. In contrast to this, our study showed progression of disease in field and lab conditions within 15 and 30 days, respectively. It is in accordance with a study done by Narmani and Arzanlou (2015). They assessed the pathogenicity of C. chrysosperma associated with trunk disease of grapevine in Northern Iran within 28 days.

In mycology, these studies are routinely used for taxonomical classification at family level but do not provide accurate framework upto species level due to variations in shape and size as well as cultivation during studies of fungal diversity. To overcome these limitations, progress has been done in the past few years in DNA barcoding which involves approaches based on DNA sequencing (Xu, 2016). The ITS DNA region of fungal isolates has been reported as the most widely sequenced and a powerful recognition system to identify and describe diverse group of fungal specimens universally. White et al. (1990) described ITS primers for the first time as conserved nucleotide sequences/regions of $18 \mathrm{~S}, 5.8 \mathrm{~S}$ and $28 \mathrm{~S}$ rRNA genes which amplify the non-coding regions between them. Thus, in this study, the primary fungal barcode, i.e., ITS region of nuclear ribosomal RNA gene cluster (Schoch et al., 2012) has been used for confirming the species level identification of canker causing fungus $C$. chrysosperma in $S$. alba. Although, the search was restricted to the sequences in the database that correspond to our subset because it has been reported that there are only twenty-three species sequences of Cytospora had been deposited in GenBank (Norphanphoun et al., 2017). Limitation of molecular data from type specimens clogs the ability to properly identify the Cytospora taxa to the species-level.

\section{Conclusion}

In present investigation, a canker causing pathogen Cytospora chrysosperma was successfully isolated and identifiedfor the first time by its morphological and molecular characters including primary barcode from symptomatic hosts of Salix which are widespread in cold desert area of Himachal Pradesh. This study not only provides an insight for seriousness and contribution of this pathogen in reduced quality and yield of hardwoods and coniferous trees in North India but also define a rapid and universal future strategy for its isolation. Although, some more robust methods can be applied to fulfil additional criteria with more accuracy at molecular level.

\section{Acknowledgements}

The authors are very grateful to Department of Biotechnology, Dr. Y.S.P. U.H.F. Nauni, Solan, H.P. for facilitating implementation and completion of this research work, also for the use of facilities and administrative support throughout the conduct of this study.

\section{Conflict of interest}

The authors declare no conflicts of interest related to this article.

\section{References}

Abbasi, K.; Abbasi, S.; Fotouhifar, K. B.; Zebarjadi, A. R. and Cheghamirza, K. (2011). Genetic diversity of Cytospora chrysosperma isolates obtained from Iranian walnut trees using molecular markers. African Journal of Biotechnology, 10(70):15710-15716.

Adams, G. C.; Wingfield, M. J.; Common, R. and Roux, J. (2004). Phylogenetic relationships and morphology of Cytospora species and related teleomorphs (Ascomycota, Diaporthales, Valsaceae) from Eucalyptus. Studies in Mycology, 52:1-144.

Adams, G. C.; Roux, J. and Wingfield, M. J. (2006). Cytospora species (Ascomycota, Diaporthales, Valsaceae): Introduced and native pathogens of trees in South Africa. Australasian Plant Pathology, 35:521-548.

Arzanlou, M.; Moshari, S.; Bakhshi, M. and Khodaei, S. (2012). First report of Botryosphaeria dothidea associated with grapevine decline disease in Iran. Australasian Plant Disease Notes, 7(1):197-200.

Callan, B. E. (1998). Diseases of Populus in British Columbia: A diagnostic manual. Ottawa: Natural Resources Canada, Canadian Forest Service.

Country Report. (2012-2015). Poplars and Willows in India. National Poplar Commission of India Forest Research Institute. P.O. New Forest, Dehradun, Uttarakhand India.

Donk, M. A. (1964). Nomina conservanda proposita I. Proposals in fungi. Deuteromycetes. Regnum Vegetabile, 34:7-15.

Doyle, J. J. and Doyle, J. L. (1990) A rapid DNA isolation procedure for small amount of fresh leaf tissue. Phytochemistry Bulletin, 19:11-15.

Fan, X. L.; Bezerra, J. D. P.; Tian, C. M. and Crous, P. W. (2019). Cytospora (Diaporthales) in China. Persoonia-Molecular Phylogeny and Evolution of Fungi.

Fan, X. L.; Liang, Y. M.; Ma, R. and Tian, C. M.(2014). Morphological and phylogenetic studies of Cytospora (Valsaceae, Diaporthales) isolates from Chinese scholar tree, with description of a new species. Mycoscience, 55:252-259.

Goltapeh, E.M.; Mahdizadeh, V. and Safaie, N. (2011). Diversity of Macrophomina phaseolina based on morphological and genotypic characteristics in Iran. The Plant Pathology Journal, 27(2):128-137.

Granel, T.; Robinson, B.; Mills, T.; Clothier, B.; Green, S. and Fung, L. (2002). Cadmium accumulation by Willow clones used for soil conservation, stock fodder and phytoremediation. Australian Journal of Soil Research, 40:1331-1337.

Grove, W. (1923). The British species of Cytospora. Bulletin of Miscellaneous Information, Royal Botanic Gardens, Kew, pp:1-30

Kepley, J. B. and Jacobi, W. R. (2000). Pathogenicity of Cytospora fungi on six hardwood species. Journal of Arboriculture, 26(6): 326-331.

Lawrence, D.P.; Travadon, R.;Pouzoulet, J.; Rolshausen, P. E.; Wilcox, W. F. and Baumgartner, K. (2017). Characterization of Cytospora isolates from wood cankers of declining grapevine in North America, with the descriptions of two new Cytospora species. Plant Pathology, 66:713725 . 
Limb, R.; Marlow, C. B. and Jacobson, B. (2003). What causes Willow dieback? Rangelands, 25:14-17.

Long, W. H. (1918). An undescribed canker of poplars and Willows caused by Cytospora chrysosperma. Journal of Agricultural Research, 8(6):331-345.

Mabberley, D. J. (1997). The plant book: A portable dictionary of the vascular plants. Cambridge University Press.

Marshall, K.N.; Hobbs, N.T. and Cooper, D.J. (2013). Stream hydrology limits recovery of riparian ecosystems after wolf reintroduction. In: Proceedings of the Royal Society B, 280:20122977.

Mehrabi, M.; Mohammadi, Goltapeh, E. and Fotouhifar, K. B. (2011). Studies on Cytospora canker disease of apple trees in Semirom region of Iran. Journal of Agricultural Technology, 7(4):967-982.

Narmani, A. and Arzanlou, M. (2015). ITS sequence data and morphology differentiate Cytospora chrysosperma associated with trunk disease of grapevine in northern Iran. Journal of Plant Protection Research, 55(2), p. 117

Norphanphoun, C.; Doilom, M.; Daranagama, D. A.; Phookamsak, R.; Wen, T. C.; Bulgakov, T. S. and Hyde, K. D. (2017). Revisiting the genus Cytospora and allied species. Mycosphere, 8(1):7-7.

Rossman, A. Y.; Adams, G. C.; Cannon, P. F.; Castlebury, L. A.; Crous, P. W. (2015) Recommendations of generic names in Diaporthales competing for protection or use. IMA Fungus, 6:145-154.
Schoch, C. L.; Seifert, K. A.; Huhndorf, S.; Robert, V.; Spouge, J. L.; Levesque, C. A.; Wen, Chen and Fungal Barcoding Consortium. (2012).Nuclear ribosomal internal transcribed spacer (ITS) region as a universal DNA barcode marker for Fungi. Proceedings of the National Academy of Sciences, 109(16):6241-6246.

Sharma, R. C.; Singh, N. B.; Tripathi, D. and Sood, A. (2011). Status and distribution of Willow mortality in Lahaul and Spiti cold desert of Himachal Pradesh. Indian Forester, 119(8):196-202.

Sinclair, W. A.; Lyon, H. H. and Johnson, W. T.(1987). Diseases of trees and shrubs. Cornell University Press: Ithaca, NY

Spielman, L. J. (1985). A monograph of Valsa on hardwoods in North America. Canadian Journal of Botany, 63:1355-1378.

Tisserat, N. A. (2004). Canker diseases of trees. Kansas State University County Extension Councils, Extension Districts, and United States Department of Agriculture Cooperating. MF 2658.

Wang, Z.; Nilsson, R. H.; James, T. Y.; Dai, Y. and Townsend, J. P. (2016) Future perspectives and challenges of fungal systematics in the age of big data. In: Biology of Microfungi, (pp. 25-46). Springer, Cham.

White, T.; Bruns, T.; Lee, S. and Taylor, J. (1990). PCR protocols a guide to methods and applications, chapter amplification and direct sequencing of fungal ribosomal rna genes for phylogenetics, pp: $315-322$.

Xu, J. (2016). Fungal DNA barcoding. Genome, 59(11):913-932. 